\title{
Warm winters challenge the cultivation of temperate species in South America-a spatial analysis of chill accumulation
}

\author{
Eduardo Fernandez $^{1}$ (D) Lars Caspersen $^{1} \cdot$ Ilja Illert $^{1} \cdot$ Eike Luedeling $^{1}$
}

Received: 22 July 2021 / Accepted: 21 November 2021/Published online: 11 December 2021

(c) The Author(s) 2021

\begin{abstract}
Winter chill accumulation plays a crucial role in determining the moment of bud burst in temperate fruit and nut trees, and insufficient chill can greatly limit yield potentials. To assess future cultivation options for such species in South America, we estimated winter chill through a spatial analysis. We used historical data (1980-2017) from 158 weather stations to calibrate a weather generator and produce temperature data for 10 historical and 60 future scenarios. We computed Safe Winter Chill (SWC, corresponding to the 10th quantile of a chill distribution) for the period 1980-2017 and for all historical and future weather scenarios and developed a framework to interpolate SWC for the continent using the Kriging method. To improve the interpolation, we applied a 3D correction model based on two co-variables (means of daily temperature extremes in July). Our results suggest important chill declines in southern Brazil and central Chile. By 2050 under the global warming scenario RCP4.5 (Representative Concentration Pathway), absolute SWC in these regions may reach a median of 18.7 and 39.6 Chill Portions (CP), respectively. Projections are most alarming for a strong global warming scenario (RCP8.5). In southern South America, adequate SWC levels of about $60 \mathrm{CP}$ may be expected even under the RCP8.5 scenario. Our results highlight the need for climate change adaptation measures to secure temperate fruit production in important growing regions of South America. The procedure we developed may help farmers and practitioners across South America estimate future SWC to adapt their orchards to future challenges.
\end{abstract}

Keywords Dormancy $\cdot$ Chill requirement $\cdot$ Deciduous trees $\cdot$ Temperate species $\cdot$ Chill map

\section{Introduction}

Woody species that evolved in temperate climate regions enter a dormancy phase in winter that allows these plants to withstand cold and freezing temperatures. During dormancy, all visible growth is suspended until the onset of favorable conditions in spring (Fadón et al.

Eduardo Fernandez

efernand@uni-bonn.de

1 Department of Horticultural Sciences, Institute of Crop Science and Resource Conservation (INRES), University of Bonn, 53121 Bonn, Germany 
2020a). Detecting the right moment to overcome dormancy and resume growth is essential for these species. While restarting the growing period too early can expose buds and other structures to damaging frost, a late resumption of growth may diminish the time available for development in spring and summer (Luedeling 2012). Temperate species determine the right moment to overcome dormancy by sensing and recording the duration of cold (chilling period) and warm conditions (forcing period) throughout winter (see Fadón et al. 2020a for a review). Once these species have experienced a certain period under both chilling and forcing conditions (meeting their chill and heat requirements-CR and HR, respectively), dormancy is broken and meristems resume growth (Campoy et al. 2011; Fadón et al. 2020a; Saure 1985; Vegis 1964). Many of the most popular fruit tree species (e.g., apples, pears, peaches, and sweet cherries), some of which are cultivated worldwide in a range of climates, experience such a dormancy phase during winter. The amount of chill and heat required to break dormancy varies greatly between species and even cultivars, mainly depending on the region of origin and the breeding history (Denardi et al. 2019; Kwon et al. 2020). Insufficient chill levels can have negative impacts on flowering and possibly fruit set (Erez 2000; Lavee and May 1997), leading to reductions in yield potentials. Knowledge of current and future chill levels in places where such species are cultivated may support farmers and orchard managers in making appropriate decisions to secure temperate fruit production in a warming climate.

Land use changes and anthropogenic emissions of greenhouse gases have already increased global temperatures by about $1{ }^{\circ} \mathrm{C}$ (likely range from 0.8 to $1.2{ }^{\circ} \mathrm{C}$ ) compared with pre-industrial levels (Allen et al. 2018). Projections for future scenarios expect this warming trend to continue at an accelerating rate over the next few decades (IPCC 2021). Before 2021, the Intergovernmental Panel on Climate Change (IPCC) suggested the use of a range of global warming scenarios known as Representative Concentration Pathways (RCPs) to bracket the plausible range of future climates. The standard set of scenarios comprises RCP2.6, RCP4.5, RCP6.0, and RCP8.5 (IPCC 2014). An RCP describes the additional radiative forcing (in $\mathrm{W} \mathrm{m}^{-2}$ ) by the end of the twenty-first century compared with pre-industrial levels, which mainly results from atmospheric greenhouse gases and air pollutant concentrations (van Vuuren et al. 2011). Whereas RCP2.6 suggests the implementation of a strong set of measures to reduce greenhouse gas emissions, RCP8.5 represents a scenario where no major changes are implemented (IPCC 2014). In the new assessment report (i.e., AR6), the IPCC suggests five new illustrative emission scenarios referred to as Shared Socioeconomic Pathways (SSP, IPCC 2021). These new scenarios include a new low end for future emissions, which leads to global warming below $1.5{ }^{\circ} \mathrm{C}$ by 2100 . Since the AR6 was released very recently, we use the former set of scenarios proposed by the IPCC in 2014.

In the context of global warming, winter chill accumulation has received substantial attention from scientists, farmers, and orchard managers, as this agroclimatic factor may become limiting in many important growing regions of temperate fruit (Luedeling et al. 2009; Rodríguez et al. 2019). In a recent assessment in Tunisia, Benmoussa et al. (2020) reported that current chill levels in many growing areas of the country may already be insufficient for a number of cultivars of peach, pistachio, and almond. The results of the study by Benmoussa et al. (2020) suggest that species and cultivars requiring about 40 Chill Portions (according to the Dynamic Model, Fishman et al. 1987a, 1987b; Erez et al. 1990) to overcome dormancy can only be grown in mid- to high-elevation regions of northwest Tunisia under warmer scenarios. Understanding and forecasting chill levels can help farmers and orchard managers improve species or cultivar selection and adopt strategies to mitigate the negative impacts of climate change on tree dormancy. 
Previous studies have assessed the impacts of climate change on agroclimatic metrics in different regions and climates. Projections suggest a major chill decline in Mediterranean climate areas such as the Central Valley of California, Tunisia, and some areas of Australia, Chile, Oman, and Spain (Benmoussa et al. 2020; Buerkert et al. 2020; Darbyshire et al. 2016; Fernandez et al. 2020b; Rodríguez et al. 2019). In other regions such as Patagonia in Argentina, projections are less alarming regarding chill decline and suggest increasing levels of heat during the growing season, which may improve conditions for fruit production (del Barrio et al. 2021). Many of the studies mentioned above assessed the impacts of climate change on specific locations by using weather data recorded in situ. Although this approach produces relevant information on historical and future climatic trends, analyzing chill levels in specific locations may restrict the applicability of possible recommendations to only the sites where data were recorded, with farmers outside these locations remaining without adequate support. Recent studies by Benmoussa et al. (2020) and Rodríguez et al. (2019) have addressed this limitation by using spatial interpolation of site-specific chill estimates. In addition to spatial interpolation of simulation data, Benmoussa et al. (2020) accounted for the elevation profile of the region to generate a chill surface for Tunisia. The elevation profile in a region has previously been demonstrated to be an important factor modulating chill accumulation in mountainous regions (Alburquerque et al. 2008; Buerkert et al. 2020). Besides the elevation profile, other proxies of chill accumulation that are related to specific geographic or climatic characteristics of a region may help interpolate chill levels for large areas where the scarcity of weather data recorded in situ is a limiting factor.

South American agriculture contributes to local and global food security. Some regions of Peru, Brazil, Argentina, and Chile are characterized by substantial production of temperate fruits, which places these countries among the most relevant exporters of fresh fruit at the global scale (CAFI 2019; ODEPA 2017). To secure the cultivation of temperate species among the different climates observed on the continent, decision makers, farmers, and orchard managers must be provided with adequate recommendations based on up-todate knowledge. At present, the only available map of chill accumulation that includes the whole region was produced by Luedeling et al. (2011) in a global analysis implemented about a decade ago. In their study, Luedeling et al. (2011) used the A2, A1B, and B1 scenarios of greenhouse gas emissions for temperature projections (with A1B and B1 being comparable to RCP6.0 and RCP4.5, respectively according to the US Global Change Research Program (Global Change 2021)). A regional analysis for southern Brazil using the Chilling Hours model (Weinberger 1950) was reported by Wrege et al. (2010). While the results of the study by Luedeling et al. (2011) and Wrege et al. (2010) provided useful insights at a global and regional scale, respectively, a continental analysis with updated warming scenarios is likely to improve our understanding of the potential risks regarding chill levels for farms cultivating temperate trees in different regions of South America.

The main aim of this work was to estimate and map historical and future chill levels for South America. We quantified chill accumulation in terms of Chill Portions (CP) according to the Dynamic Model (Erez et al. 1990; Fishman et al. 1987a, 1987b). Among other commonly used chill modeling approaches (e.g., the Chilling Hours model cited by Weinberger (1950) or the Utah Model developed by Richardson et al. (1974)), the Dynamic Model has emerged as the most reliable model for chill estimation in mild-winter climates due to its biologically credible structure (Fernandez et al. 2020c; Luedeling and Brown 2011; Zhang and Taylor 2011). In brief, the Dynamic Model states that chill accumulates in a two-step process that is modulated by cold and subsequent moderate temperatures (Luedeling 2012). Using this chill model, we estimated chill levels for 158 locations across South America using data recorded in situ between 1980 and 2017 by weather stations across the continent. 
For the past, we computed chill based on actual observations as well as based on historical weather scenarios (scenarios that represent typical climatic conditions for specific past periods). To obtain future chill levels, we used temperature projections by an ensemble of fifteen General Circulation Models (GCMs), for two RCP scenarios (RCP4.5 and RCP8.5), and for two time horizons (2050 and 2085). We then interpolated chill levels for each scenario for the whole continent using the Kriging method. We produced the final maps by correcting the linear interpolation using a model that considers the relationship between average daily minimum and maximum temperature in July and observed chill, as recorded at the weather stations.

\section{Materials and methods}

\subsection{Selection of weather stations and data collection}

We selected 158 weather stations located across South America as sources of temperature data (Fig. 1; Table S1). To select appropriate stations, we first listed 1500 weather

Fig. 1 Map of South America showing the elevation profile of the region and the weather stations we used as data sources for this study. The color scheme represents the elevation (in meters above sea level - m.a.s.1.) according to the Amazon Web Services Terrain Tiles database. Different shapes in blue represent the database accessed for downloading temperature records. 'GSOD' (triangles) stands for the Global Summary Of the Day database maintained by the National Oceanic and Atmospheric Administration (NOAA), ' $[\mathrm{CR}]^{2}$, (circles) stands for the Center for Climate and Resilience Research of the University of Chile, and 'SMN - INTA' (plus signs) represents the Argentinean databases of the National Weather Service (SMN) and the National Institute of Agricultural Technology (INTA)

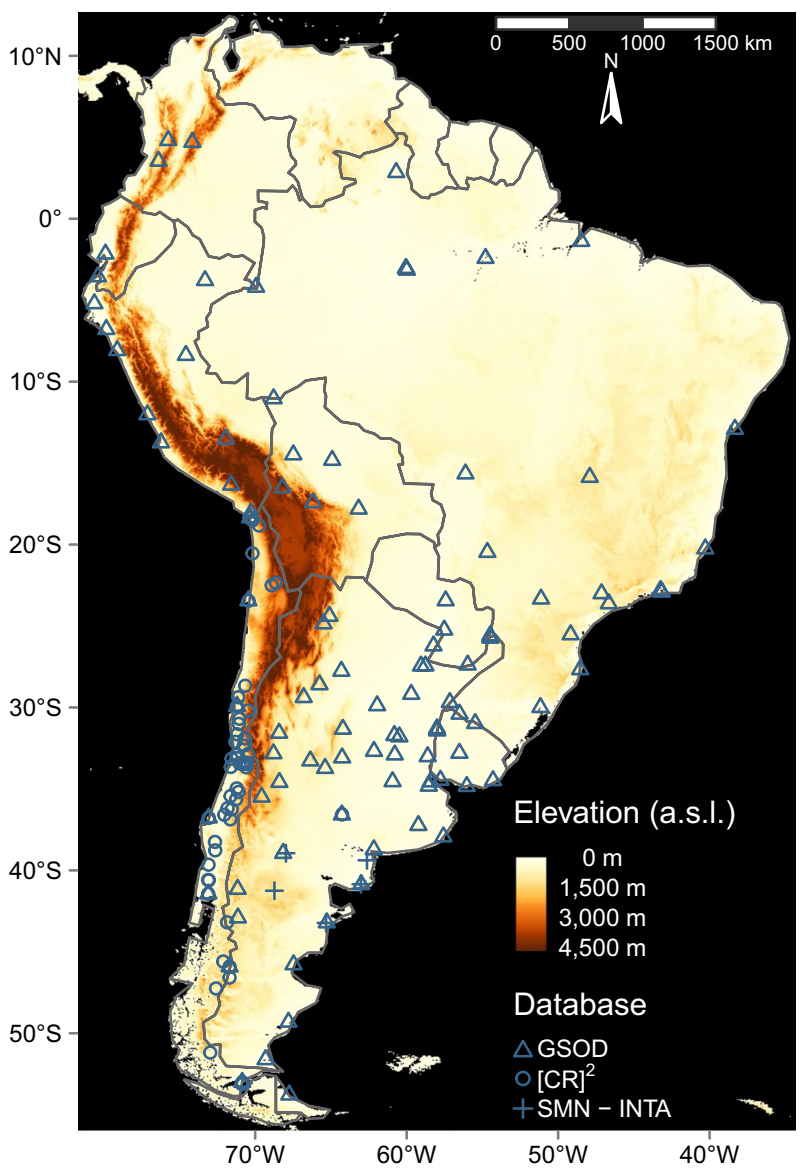


stations in South America by accessing the Global Summary Of the Day (GSOD) database through functions contained in the chillR package (Luedeling 2020). We filtered the initial set of weather stations to select those with data between January 01, 1980 and December 31,2017 . This resulted in 332 weather stations, for which we downloaded weather records from the GSOD database. After downloading, we determined the records' coverage of minimum and maximum temperatures for the intended period of this study (i.e., the chilling season between May 1 and August 31) and selected all stations whose records were at least $90 \%$ complete for at least one of the two metrics. This reduced the number of weather stations to 105 . In order to increase the reliability of the analysis, we included weather data from different sources. We accessed a Chilean network maintained by the Center for Climate and Resilience Research $\left([\mathrm{CR}]^{2}\right)$ through functions contained in the dormancyR package (Fernandez 2020). Out of 909 available weather stations across the country, we selected 58 stations that had at least 90\% data coverage for the winter period of 1980-2017. Additionally, we obtained data for 5 weather stations located in Patagonia, Argentina that fulfilled the data completeness requirement. These data were collected by the National Weather Service (SMN, https://www.smn.gob.ar) as well as the National Institute of Agricultural Technology (INTA, https://www.argentina.gob.ar/inta) and had been used in an earlier study by del Barrio et al. (2021).

\subsection{Data preparation and gap filling}

The data downloaded from the databases showed a maximum of $9.9 \%$ of missing values for daily minimum temperatures and $16.5 \%$ of missing values for daily maximum temperatures. On average, the percentage of missing values among weather stations was $~ 3 \%$ (about 145 days out of 4674) for both minimum and maximum temperatures. To fill the gaps with auxiliary data sources, we applied the procedure described in Fernandez et al. (2020c), with some modifications. In brief, we identified the 40 closest weather stations to each primary weather station that showed at least one gap. For each weather station in this auxiliary list of 40 data sources, we computed the difference relative to the primary location for all days that had records in both datasets. This procedure was implemented separately for minimum and maximum temperatures and for each month of the year. We then computed the monthly mean difference as well as the monthly standard deviation for the resulting values. We used the mean difference to adjust the data in the auxiliary dataset before filling the gaps in the primary dataset. To avoid including non-representative data, we set a threshold of $4{ }^{\circ} \mathrm{C}$ for both the monthly mean difference and standard deviation to filter the auxiliary weather stations. We applied this procedure until filling all gaps or until no more auxiliary weather stations were available.

The procedure described above resulted in complete records for most weather stations. Nonetheless, a relevant share (75 weather stations) still showed missing days after applying the patching procedure. In these cases, we filled the remaining gaps through linear interpolation (Luedeling 2018). On average, 30 days were linearly interpolated in each weather station (ranging from 1 to 214 days). For most of the stations (52 locations), the interpolated days represented periods outside the chill accumulation season, which were not relevant for further analyses. However, in 23 out of 75 weather stations, the linear interpolation procedure covered the period we later used for estimating chill accumulation (from May to August). For these stations, only between 1 and 4 days were interpolated, suggesting that our analysis was not greatly influenced by applying linear interpolation to fill data gaps (Luedeling 2018). After applying the gap-filling procedure, ten weather stations were 
removed from the analysis since these stations showed missing values for more than a month. The steps described above helped us obtain complete records of daily temperature extremes (minimum and maximum records) for 158 locations (supplementary materials Table S1) across South America for a period of 38 years.

\subsection{Historical and future scenarios}

We computed winter chill for all years on record for each weather station. Computing chill accumulation from observed weather, however, may obscure long-term trends, which are crucial for assessing future climate risks. Each computation of chill for a given year is essentially the result of a random draw from an unknown distribution of plausible temperature outcomes. This logic underlies the functioning of weather generators, which derive these unknown distributions from observed weather records and offer capabilities to draw such random samples. To characterize agroclimatic conditions in the past, we therefore generated historical weather scenarios based on the data recorded on-site. As reported in previous studies (Benmoussa et al. 2020; Buerkert et al. 2020), we used the RMAWGEN weather generator (Cordano and Eccel 2019) to produce 100 replicates of synthetic weather and characterize the typical distributions of weather conditions for particular years in the past. Weather generators are statistical models that simulate realistic random sequences of atmospheric variables such as temperature, precipitation, and wind (Wilks and Wilby 1999) based on a calibration dataset. As inputs for this tool, we used monthly means of daily minimum and maximum temperatures for each year of interest, computed via a 15-year running mean function applied to data for all years on record. This allowed us to closely follow patterns observed in the historical data. We used this procedure to generate scenarios for 1981, 1985, 1989, 1993, 1997, 2001, 2005, 2009, 2013, and 2017. For each of these years, the outputs produced by the weather generator represented plausible distributions of temperature conditions that are characteristic of the respective year.

We used the same procedure described above to generate future climate scenarios. As input for the weather generator in this case, we used monthly means of daily temperature extremes downloaded from the ClimateWizard (Girvetz et al. 2009) database maintained by the International Center for Tropical Agriculture (CIAT) using an application programming interface (https://github.com/CIAT-DAPA/climate_wizard_api). ClimateWizard contains temperature projections generated by 15 General Circulation Models (GCMs, supplementary materials Table S2) for two Representative Concentration Pathway scenarios (RCP4.5 and RCP8.5) and for a number of time horizons. For this study, we selected the periods 2035-2065 and 2070-2100, denoted by their central years 2050 and 2085. Since the ClimateWizard database contains temperature projections relative to the period 1950-2005 (by default), we implemented a baseline adjustment procedure to make the estimations comparable to our historical period. We first generated two absolute temperature scenarios based on the weather data recorded on-site. These temperature scenarios represented the conditions (mean minimum and maximum temperatures for each month) of the central years of the periods 1980-2017 (historical weather data) and 1980-2005 (baseline selected in the ClimateWizard database), respectively. We then obtained a relative temperature scenario by computing the monthly difference for each metric between these two absolute scenarios. We used the resulting relative scenario to adjust the temperature scenario obtained from ClimateWizard. The final output was used to feed the weather generator and produce 100 years of weather records based on projections by 15 GCMs. 


\subsection{Winter chill estimation}

We computed winter chill for (i) all years on record, (ii) all synthetic years for each historical scenario, and (iii) all synthetic years for each combination of RCP, time horizon, and GCM. For the sake of standardization and comparison among past and future scenarios as well as with results from previous studies, we selected fixed dates for the start and end of the chill accumulation season. Following dates used in previous studies (see Fernandez et al. 2020c for example), we defined the chill accumulation season as between May 1 and August 31 for each year. We used the Dynamic Model (Erez et al. 1990; Fishman et al. 1987a, 1987b) to compute chill, since this model has emerged from a number of model comparison studies as the most credible tool for explaining the process of chill accumulation in temperate trees (Fernandez et al. 2020c; Luedeling and Brown 2011; Zhang and Taylor 2011). Because this model requires hourly temperatures as input, we derived hourly records from daily temperature extremes and the latitude of each weather station. To this end, we estimated temperatures based on an idealized daily temperature curve consisting of a sine function for daytime warming and a logarithmic decay function for nighttime cooling (Almorox et al. 2005; Linvill 1990).

We summarized the chill distributions for each weather station and scenario according to the Safe Winter Chill concept (SWC, Luedeling et al. 2009). Safe Winter Chill is the 10th percentile of the chill distribution, which represents the chill level that is likely to be met in $90 \%$ of years (Luedeling et al. 2009). Regarding future chill levels computed across the 15 GCMs, we summarized the Safe Winter Chill values according to 'optimistic', 'intermediate', and 'pessimistic' GCM projections. These climate model classes represented the 85 th, 50th, and 15th quantile of the chill distribution across all GCMs (15 values) for each combination of RCP and time horizon, respectively.

\subsection{Predictors of Safe Winter Chill}

To estimate winter chill accumulation in areas lacking observational data, we identified geographic and environmental variables correlated with SWC. We first assessed the linear relationship between SWC observed on site and the variables of interest. To estimate the potential effect of latitude on such a relationship, we divided the list of weather stations into 12 groups from $5^{\circ} \mathrm{N}$ to $55^{\circ} \mathrm{S}$. We tested the distance to the ocean (in $\mathrm{km}$ ), the elevation above sea level (in $\mathrm{m}$ ), and the average of daily minimum and maximum temperatures in July (in ${ }^{\circ} \mathrm{C}$ ). Based on the results of this analysis, we decided to use the average of daily minimum and maximum temperatures in July as predictors of SWC for the spatial interpolation.

\subsection{Spatial chill interpolation}

We developed a methodological framework (Fig. 2) for spatial interpolation of SWC, building on methods described by Benmoussa et al. (2020). We first interpolated an SWC surface using an ordinary Kriging approach. Since such Kriging surfaces are only based on data for the particular locations used for the interpolation, they may contain large errors for many other regions. To account for the considerable variation in climate and geography across the continent, which is known to affect chill accumulation, we established a correction procedure based on two co-variables with known spatial 


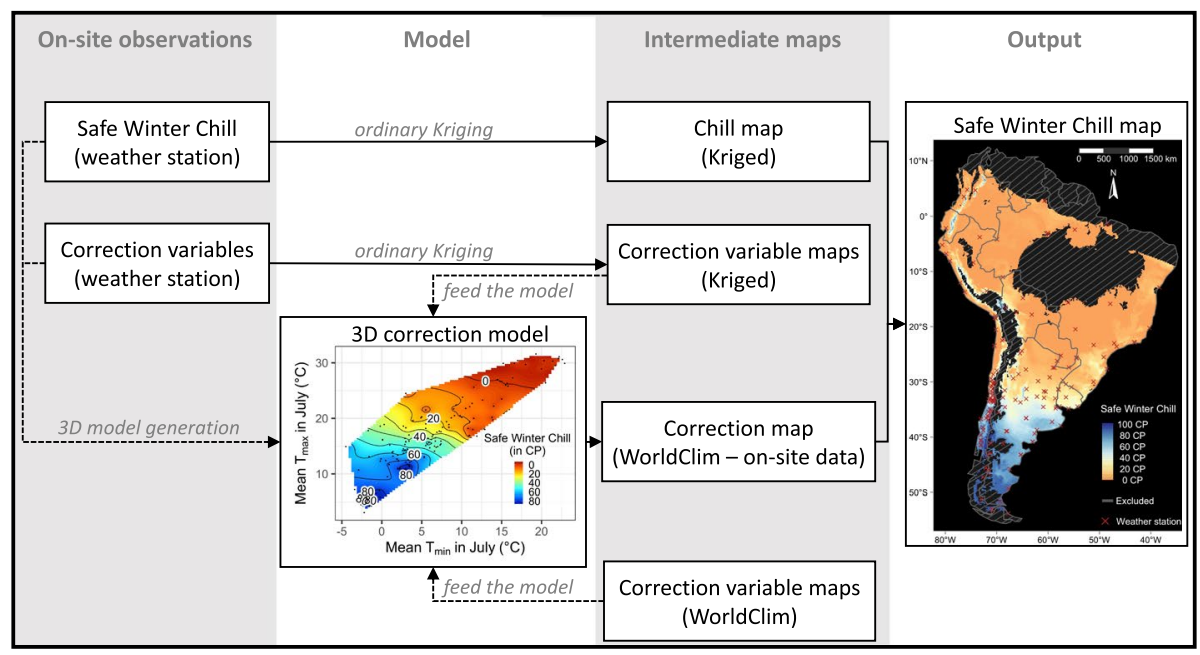

Fig. 2 Framework for spatial interpolation of winter chill across South America. In the first stage, we applied ordinary Kriging to data for weather station locations to obtain surfaces of Safe Winter Chill (SWC) and mean daily minimum and maximum temperatures in July using data recorded in situ ('Chill map' and 'Correction variable maps' nodes in the figure). In a second step, we obtained gridded data for our correction co-variables from the WorldClim database ('Correction variable maps' node). Using data from the weather stations, we then generated a ' $3 \mathrm{D}$ correction model' based on the relationship between monthly means of daily temperature extremes (minimum and maximum records) and observed SWC. We used this model to estimate SWC values from the co-variables (mean daily minimum and maximum temperatures in July) from both data sources (WorldClim and weather stations) to obtain the SWC correction map ('Correction map' node). Finally, we applied this SWC correction map to the original Kriged map to produce the final SWC maps for all scenarios

distributions. Our correction variables, which may serve as proxies for chill accumulation, were the means of daily minimum and maximum temperatures in July. We downloaded historical gridded data (1970-2000) for these co-variables with a spatial resolution of 30 arcseconds $\left(\sim 1 \mathrm{~km}^{2}\right)$ from the WorldClim database (Fick and Hijmans 2017). In addition to these gridded data, we used ordinary Kriging to produce interpolated surfaces for the same variables recorded in situ by the weather stations, which were used to characterize the temperature conditions that were represented by the original Kriged SWC surface. To include only representative data, we excluded weather stations for which the difference between proxy variable values from WorldClim and the weather stations was greater than $2{ }^{\circ} \mathrm{C}$ (see supplementary materials Fig. S1).

For each scenario, we created a 3D correction model by generating a surface contour plot relating SWC to mean daily minimum and maximum temperatures in July computed for the weather stations (Fig. 2). To create the 3D correction model, we assumed that observed SWC values are a function of the daily minimum and maximum temperatures in July and implemented ordinary Kriging to predict a continuous surface. We implemented this procedure using functions within the fields package for R (Nychka et al. 2017). We interpolated a similar surface relating SWC to values of the co-variables for the same locations from the WorldClim database. For each point on the map, we then subtracted the SWC value from the contour plot based on weather station data from the contour plot based on WorldClim data. The result was a correction SWC map that we added to the original SWC values obtained through ordinary Kriging (Fig. 2). We note that in this correction 
procedure, we assumed that the error in the original SWC Kriging is related to the difference between co-variables from both databases (WorldClim and on-site). We set the correction procedure to generate chill values $\geq 0$ considering that the Dynamic Model returns positive chill values only. Additionally, we excluded all regions (using a hatching layer to mask them in all maps) for which the combination of mean daily minimum and maximum temperatures in July had no observed (on-site) values of SWC in the 3D correction model (see supplementary materials Fig. S2).

\subsection{Cross-validation}

We implemented a cross-validation procedure to assess the reliability of our spatial interpolation approach. After excluding all weather stations that featured a difference $>2{ }^{\circ} \mathrm{C}$ compared with the WorldClim data for mean daily minimum or maximum temperatures in July, we randomly split the set of weather stations into 7 groups. Each of the seven groups was once treated as a validation data set, while the remaining data sets were combined into a training set to compile the final SWC maps following our interpolation framework (Fig. 2). We then compared the values for SWC computed with the training data set to the values observed in the validation set to obtain the residual values (observed minus predicted). Since the grouping can affect the calculation of residuals, we repeated the crossvalidation procedure 5 times, and computed the mean residual across these 5 repetitions. We iterated this process over the observed and simulated historical scenarios as well as the 'pessimistic', 'intermediate', and 'optimistic' climate model classes by 2050 and 2085 under RCP4.5 and RCP8.5. We summarized the results of the cross-validation procedure by computing the median and standard deviation of residuals across scenarios.

\subsection{Data processing, analyses, and figure preparation}

All data processing, analyses, and figure preparation were implemented in the R programming environment ( $\mathrm{R}$ Core Team 2020). Analyses related to agroclimatic metrics were performed with functions of the chillR package (Luedeling 2020). For figure preparation, we used the ggplot2 (Wickham 2016) and tmap (Tennekes 2018) packages. Scripts for reproduction of all data processing steps (including figure generation) are available in a public GitHub repository (https://github.com/EduardoFernandezC/chill_south_america).

\section{Results}

To facilitate visualization of results, we only included figures representing key scenarios (e.g., RCP4.5-2050 and RCP8.5-2085 for future conditions) in the main text. For all combinations of RCP scenario, time horizon, and climate model class, see our supplementary materials.

\subsection{Predictors of SWC}

The results of our analysis suggest that the means of daily minimum and maximum temperatures in July may serve as the best predictors of winter chill accumulation in South America when compared with elevation and distance from the ocean (Fig. S3). When 
assuming a linear relationship between SWC and these variables, the overall coefficient of determination of the regressions showed values of 0.674 for the mean minimum and 0.796 for the mean maximum temperature. We detected much weaker correlations between SWC and distance to the ocean $\left(R^{2}\right.$ of 0.169$)$ and elevation above sea level $\left(R^{2}\right.$ of 0.512$)$. When including the interaction between the variables and the latitude group, $R^{2}$ values tended to increase considerably. For the means of daily minimum and maximum temperature, this correlation metric increased to 0.905 and 0.933 , respectively. For the remaining variables (distance to the ocean and elevation), the $R^{2}$ increased to 0.857 and 0.880 .

\subsection{Cross-validation}

Our cross-validation approach resulted in rather small residuals across weather stations, but also identified some notable outliers (Fig. 3). Overall, the median residual was -0.85 $\mathrm{CP}$, considering all weather stations showing residual values after the cross-validation procedure. It should be noted that the procedure did not produce residual values for 17 weather stations. This is explained by these weather stations falling outside the boundaries of the 3D correction model (created with the training dataset) when included in the evaluation dataset. Median residuals ranged from-3.86 CP (Q25\%) to $0.93 \mathrm{CP}(\mathrm{Q} 75 \%)$ and showed maximum values of $-32.1 \mathrm{CP}$ (Teniente Alejandro Velasco Astete International; 13.5 $\mathrm{S} ; 71.9^{\circ} \mathrm{W} ; 3310.1$ m.a.s.1.) for the lower bound and 7.16 CP (Digua Embalse; $36.3^{\circ}$ $\mathrm{S} ; 71.6^{\circ} \mathrm{W} ; 390.0 \mathrm{~m}$.a.s.1.) for the upper bound. The standard deviation of the residuals ranged from 1.53 $\mathrm{CP}(\mathrm{Q} 25 \%)$ to $3.70 \mathrm{CP}(\mathrm{Q} 75 \%)$ and showed a median of $2.54 \mathrm{CP}$ across weather stations. The maximum standard deviation was $11.6 \mathrm{CP}$, identified for the weather station Teniente Alejandro Velasco Astete International $\left(13.5^{\circ} \mathrm{S} ; 71.9^{\circ} \mathrm{W}\right)$ located at 3310.1 m.a.s.1..

Fig. 3 Residuals (observed minus estimated values) obtained from the cross-validation procedure we implemented for the interpolation of Safe Winter Chill. The standard deviation of the residuals ('SD residual' in Chill Portions $(\mathrm{CP})$ ) is represented by the bubble size, whereas the median value for the residuals is shown by the color. The histogram in the bottom-right corner shows the distribution of the median residuals across scenarios. The red crosses in the map represent the weather stations falling outside the $3 \mathrm{D}$ correction model generated with the training data set in the cross-validation procedure. For these weather stations, we did not obtain values for the residuals

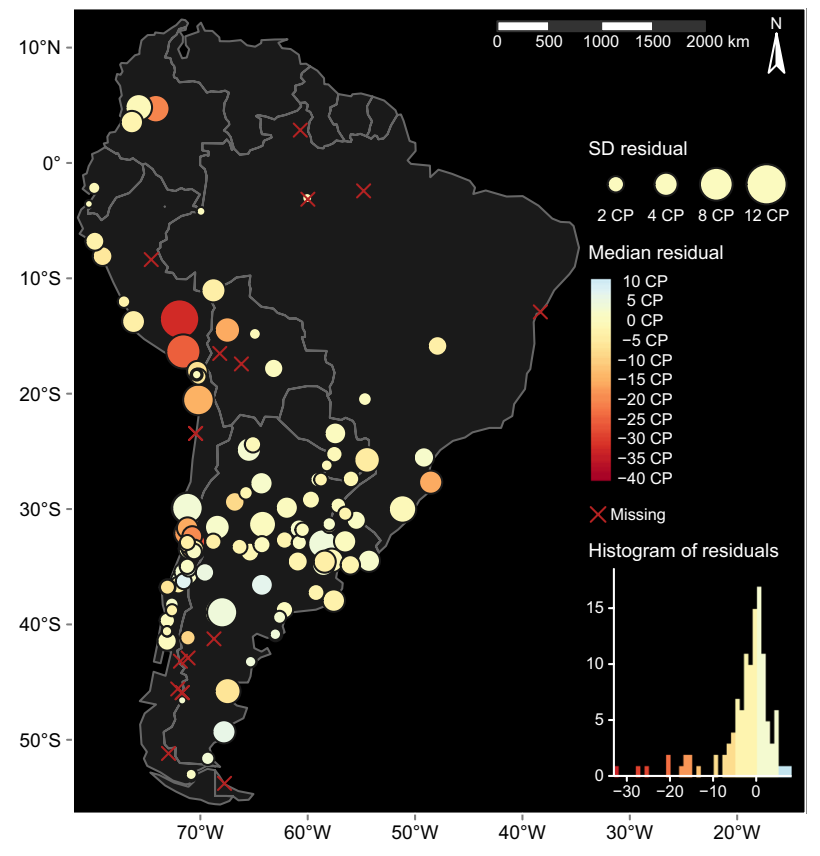




\subsection{Safe Winter Chill for historical scenarios}

Historical SWC in South America varied widely across the various subregions of the

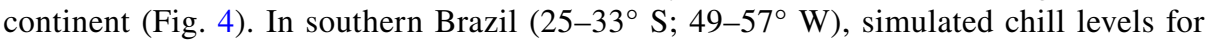
historical scenarios ranged from $18.0 \mathrm{CP}$ (5\% quantile (Q5\%)) to $37.7 \mathrm{CP}$ (95\% quantile (Q95\%)), with a median of 25.0 CP. In northern Patagonia, Argentina (37-46 S; $61-70^{\circ} \mathrm{W}$ ), SWC values showed a median of $72.2 \mathrm{CP}$ (from $64.2 \mathrm{CP}$ for Q5\% to 84.5 $\mathrm{CP}$ for $\mathrm{Q} 95 \%)$. We estimated historical median $\mathrm{SWC}$ values ranging from $36.7 \mathrm{CP}$ (Q5\%) to $51.5 \mathrm{CP}(\mathrm{Q} 95 \%)$ for the Central Valley of Chile $\left(30-37^{\circ} \mathrm{S} ; 70-77^{\circ} \mathrm{W}\right)$. Some regions of Colombia, Ecuador, Peru, and Bolivia (between $10^{\circ} \mathrm{N}$ and $25^{\circ} \mathrm{S}$ ) showed considerable SWC levels in the Andes and adjacent regions (Fig. 4).

Comparison of SWC calculations for the simulated historical scenarios for 1981 and 2017 indicated that, across the whole continent, changes ranged from $-34.3 \mathrm{CP}$ to 16.5 $\mathrm{CP}$ (Fig. 4). Although the absolute change was relatively small for most locations, we estimated considerable chill declines near the Andes in Colombia $\left(7-2^{\circ} \mathrm{N} ; 72-77^{\circ} \mathrm{W}\right)$, in the Central Valley of Chile, and in northern Patagonia, Argentina. In these regions, average SWC change reached -7.9 CP $(-14.8 \mathrm{CP}$ for Q5\% and $0 \mathrm{CP}$ for Q95\%), -5.7 CP (-8.4 CP for Q5\% and -3.4 CP for Q95\%), and -4.5 CP (-6.8 CP for Q5\% and -1.8 $\mathrm{CP}$ for $\mathrm{Q} 95 \%)$, respectively. In southern Brazil, the overall change in SWC between
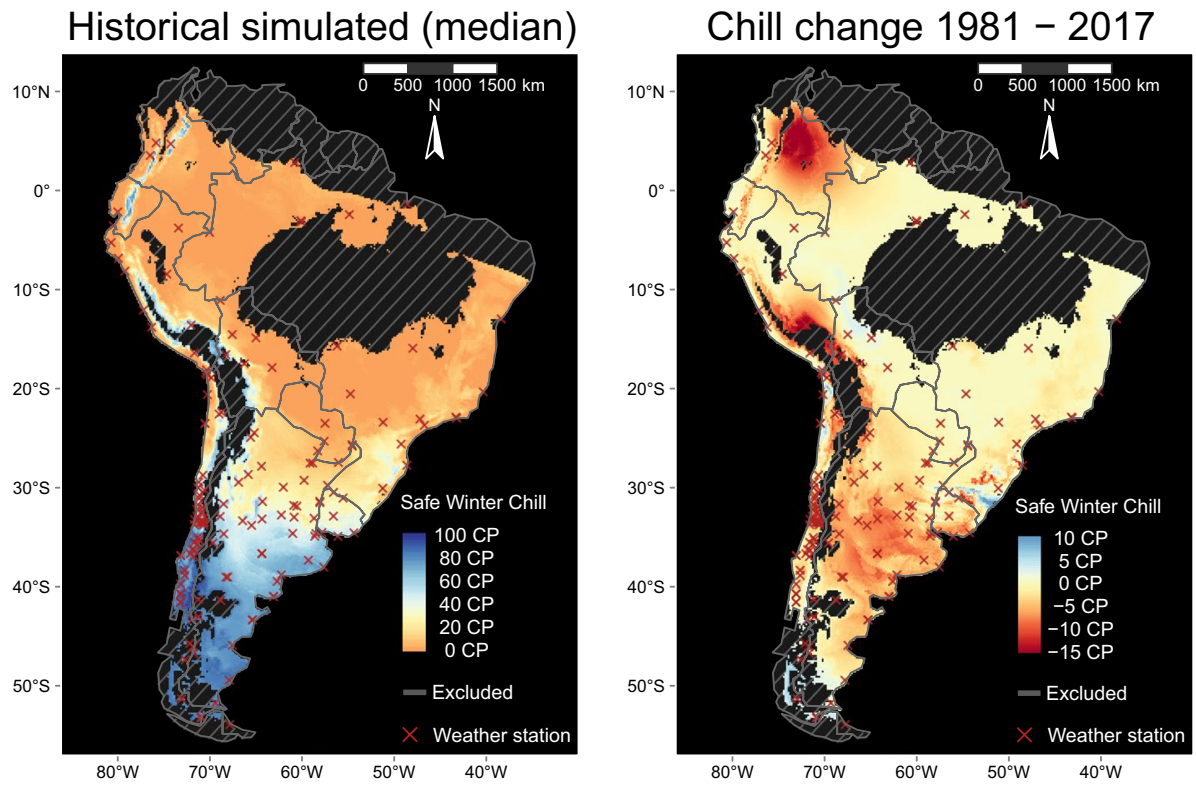

Fig. 4 Historical Safe Winter Chill (SWC) maps for South America. 'Historical simulated' represents the median SWC computed from simulated scenarios for the years 1981 to 2017 (10 scenarios spanning the period of interest with 100 values per scenario). 'Chill change 1981-2017' shows the change in SWC computed from the historical simulated scenarios for the respective years (2017 minus 1981). We show SWC in Chill Portions (CP) according to the Dynamic Model. The grey hatched areas ('Excluded' in the legend) in the maps indicate regions where the combination of mean daily minimum and maximum temperatures in July fell outside the boundaries of the 3D correction model for the respective scenario. The red crosses represent the locations of the weather stations we used in the analysis 
1981 and 2017 was less clear, reaching a mean of $-2.5 \mathrm{CP}$ and ranging from $-10.0 \mathrm{CP}$ (Q5\%) to 4.6 CP (Q95\%).

\subsection{Absolute Safe Winter Chill under future conditions}

Our results show comparable SWC values among the climate model classes 'pessimistic' and 'optimistic' (Fig. S4 to S6). For the RCP4.5-2050 scenario, maximum SWC values across South America were about $100 \mathrm{CP}$ for the 'pessimistic' class of climate projections, and slightly lower (99.4 CP) for the 'optimistic' class. Conversely, slightly more chill was projected for the 'optimistic' class when compared with the climate model class 'pessimistic' (101.1 CP versus 101.6 CP) under the global warming scenario RCP8.5 by 2085 (Fig. S4). A considerable SWC decline was observed when comparing the same climate model class (e.g., 'pessimistic') under different RCP scenarios and time horizons (upper versus bottom panels in Fig. S4).

Regarding specific regions of the continent, absolute SWC values are likely to range from 4.9 $\mathrm{CP}(\mathrm{Q} 5 \%)$ to $28.7 \mathrm{CP}(\mathrm{Q} 95 \%)$ and reach a median of $17.0 \mathrm{CP}$ under the 'RCP4.5-2050 pessimistic' scenario in southern Brazil, a major production region of temperate fruit (Figs. S7 to S9). Growers around this region may expect SWC values of 9.9 CP (likely range between 1.4 CP and 17.7 CP-Q5\% and Q95\%, respectively) under the 'RCP8.5-2085 pessimistic' scenario. Compared with the 'pessimistic' climate model class, projections for an 'optimistic' climate projection show slightly greater SWC values by about 3.0 CP and 5.3 CP for the median for the RCP4.5-2050 and RCP8.5-2085 global warming scenarios, respectively (Fig. S7).

In northern Patagonia, Argentina, SWC is likely to reach a median of $68.9 \mathrm{CP}$ under RCP4.5 by 2050 for the 'pessimistic' climate model class (Fig. S7). For the 'optimistic' class, SWC in this region may increase to $71.3 \mathrm{CP}$ for the same combination of RCP and time horizon. For RCP8.5 by 2085, farmers can expect between $47.1 \mathrm{CP}$ (Q5\%) and 82.7 $\mathrm{CP}(\mathrm{Q} 95 \%)$ according to the 'pessimistic' climate model class and between $56.7 \mathrm{CP}(\mathrm{Q} 5 \%)$ and $85.8 \mathrm{CP}(\mathrm{Q} 95 \%)$ for the 'optimistic' class.

For the Central Valley of Chile, our projections suggest an SWC range between 25.8 CP (Q5\%) and 40.8 CP (95\%) for the 'pessimistic' climate model class of the RCP4.5-2050 scenario (median of $36.7 \mathrm{CP}$ ). By 2085 and for RCP8.5, chill levels are likely to range between 10.0 CP (Q5\%) and 32.4 CP (Q95\%), using the same climate model classification (median of $21.2 \mathrm{CP}$ ). In the 'optimistic' climate model class, SWC might reach a median of 41.9 CP for the RCP4.5-2050 scenario and 33.3 CP for the RCP8.5-2085 scenario.

\subsection{Expected changes in chill accumulation compared with the historical period}

Compared with the historical scenarios, our results suggest a notable chill decline even for the moderate global warming scenario RCP4.5 (Figs. 5 and S10 to S11). Depending on the region evaluated, chill change ranged between $-38.6 \mathrm{CP}$ and $9.9 \mathrm{CP}$ for the 'pessimistic' climate model class of the RCP4.5-2050 scenario and between-29.0 CP and 9.7 CP for the 'optimistic' class for the same RCP and time horizon combination. A much greater SWC decline by about $55 \mathrm{CP}$ and $45 \mathrm{CP}$ might be expected under the RCP8.5-2085 scenario for the 'pessimistic' and 'optimistic' climate model classes, respectively (Fig. 5).

The Central Valley of Chile is likely to emerge as one of the most affected regions across South America regarding winter chill decrease (Fig. 5). For this region, our results suggest a median decline by about $12.1 \mathrm{CP}$ by 2050 in the moderate global warming 

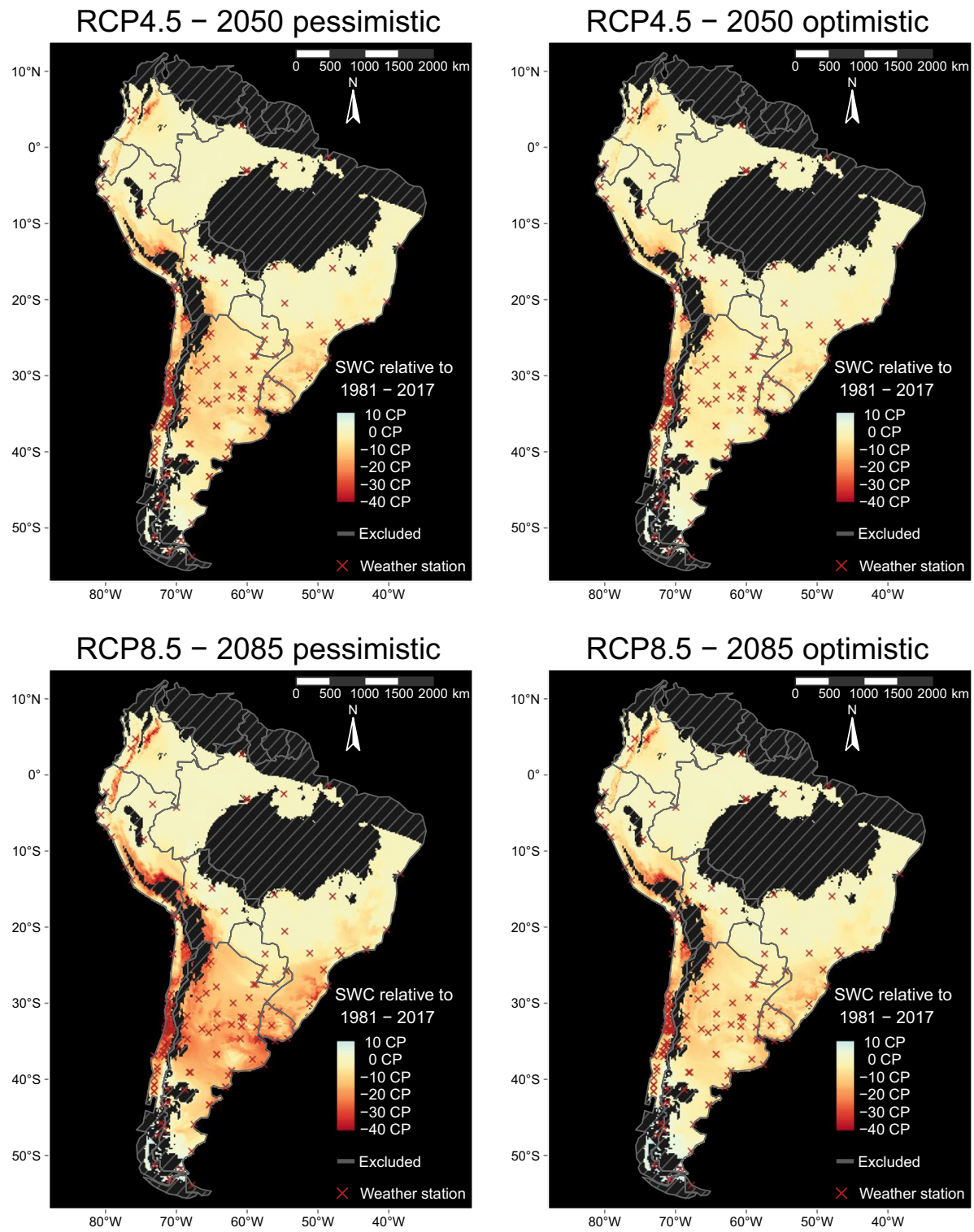

Fig. 5 Safe Winter Chill changes (SWC in Chill Portions (CP) according to the Dynamic Model) compared with the historical period 1981-2017 for South America for two global warming scenarios. We computed the change using as baseline the median SWC across ten simulated historical scenarios between 1981 and 2017. In the first row ('RCP4.5-2050 pessimistic' and 'RCP4.5-2050 optimistic' panels), we show the expected change for a moderate warming scenario for the near future using two climate model classes. In the second row ('RCP8.5-2085 pessimistic' and 'RCP8.5-2085 optimistic' panels), we show SWC changes estimated for a strong warming scenario by the far future using two climate model classes. 'Pessimistic' and 'optimistic' labels represent the 15th and 85th quantiles of the SWC distribution across the 15 General Circulation Models (see supplementary Table S2) we used in this analysis. The grey hatching ('Excluded' in the legend) in the maps indicates regions where the combination of mean daily minimum and maximum temperatures in July fell outside the boundaries of the 3D correction model for the respective scenario. The red crosses represent the location of the weather stations we used in the analysis 
scenario RCP4.5 for the 'pessimistic' climate model class. In this scenario, the likely decline may range between 16.1 CP (Q5\%) and 6.2 CP (Q95\%). The 'optimistic' climate model class of the RCP4.5-2050 scenario suggests an SWC decline between 9.9 CP (Q5\%) and 3.6 CP (Q95\%), with a median of 6.9 CP (Fig. 5). In other regions such as northern Patagonia, Argentina, and southern Brazil, comparable changes are only projected for the RCP8.5-2085 scenario for the 'pessimistic' climate model class.

\section{Discussion}

We developed a method for spatial interpolation of Safe Winter Chill on a continental scale. We used mean daily minimum and maximum temperatures in July as co-variables for estimating winter chill accumulation across South America. In a previous study conducted in the Mediterranean climate of Tunisia, Benmoussa et al. (2020) successfully used elevation above sea level as a chill proxy in the interpolation procedure. Similarly, Buerkert et al. (2020) and Alburquerque et al. (2008) highlighted the importance of the elevation of the region in determining chill levels during winter in northern Oman and southeastern Spain. In our study however, elevation above sea level was not a good proxy for winter chill accumulation, probably because of the large extent of the region as well as major intra-regional differences in climatic conditions. In general, the correlation between elevation and winter chill was high at low latitudes (between $5^{\circ} \mathrm{N}$ and $25^{\circ} \mathrm{S}$ ) but very low at locations south of $30^{\circ} \mathrm{S}$ (see Fig. S3). Along the same lines, distance to the ocean did not constitute a good proxy for winter chill accumulation across the whole continent. This and other geographic and climatic variables may serve as proxies of chill accumulation in smaller regions or for areas with low variation in topography and climatic conditions. In a highly diverse region (climatically and topographically) such as South America, only monthly means of daily temperature extremes appeared to capture the overall intra-regional variation and exhibit sufficient correlation with SWC. Using these two co-variables to supplement estimates based on on-site records proved effective in obtaining reasonable estimations of winter chill accumulation in South America and holds promise for similar regions where high-resolution datasets are scarce.

We observed large residuals for some weather stations when cross-validating the chill interpolation procedure. Among these, we highlight the weather stations Vilcuya (at 1100 m.a.s.l.) in Chile, Teniente Alejandro Velasco Astete International in Peru (at 3310 m.a.s.1.), and El Dorado International in Colombia (at 2549 m.a.s.1.). The median residuals among repetitions and scenarios for these stations reached-27.6 CP, -32.1 $\mathrm{CP}$, and $-20.8 \mathrm{CP}$, respectively. Large residuals in high-elevation areas may partially be explained by our 3D correction model failing to capture the relationship between the covariables (mean daily temperature extremes in July) and SWC in these regions. Since the 3D correction model is based on on-site data, we believe that more information from these extreme environments may improve the interpolation procedure. Large residuals may also result from particular microclimatic settings at the respective weather stations. Among the three stations with the highest residuals, two are located at high-elevation airports in relatively dense urban areas, whereas the third station is located in a narrow mountain valley. It seems plausible that correction models built without these stations (by them being part of the evaluation dataset) may not be able to represent the special climatic conditions that result from such settings. 
Our results suggest considerable chill reductions in many parts of the continent even for the moderate global warming scenario. These findings mirror the results of earlier analyses conducted for a number of regions around the globe (Darbyshire et al. 2016; Fernandez et al. 2020b; Luedeling et al. 2011; Rodríguez et al. 2019). The Central Valley of Chile emerges as a highly sensitive region regarding the impacts of global warming on winter chill accumulation. In agreement with previous studies in Chile (Fernandez et al. 2020b, 2020c), orchards located between $30^{\circ} \mathrm{S}$ and $37^{\circ} \mathrm{S}$ may experience a reduction in SWC between 6 and $16 \mathrm{CP}$ by 2050 for the RCP4.5 scenario ('pessimistic' climate model class). Analyzing the same combination of RCP and time horizon, absolute SWC levels in this region may reach a median of $36 \mathrm{CP}$, which may represent a hazardous situation for farmers cultivating high-chill species such as apple and sweet cherry. Whereas apple trees may require between 50 and $90 \mathrm{CP}$ (depending on the cultivar) to successfully overcome dormancy (Delgado et al. 2021; Fernandez et al. 2020a; Parkes et al. 2020), the chill requirement of different sweet cherry cultivars has been reported as between 30 and $86 \mathrm{CP}$ (reviewed in Fadón et al. 2020b). For southern Brazil, Wrege et al. (2010) forecasted absolute chill levels between 300 and 600 Chilling Hours (between 25 and $50 \mathrm{CP}$ using conversion factors across models from Luedeling and Brown 2011) for a scenario considering an increase of $1{ }^{\circ} \mathrm{C}$ relative to the period 1961-2000. By 2050 under the RCP4.5 scenario (which projects a likely temperature increase between 1.1 and $2.6^{\circ} \mathrm{C}$ ), our results suggest a median absolute SWC value of 17.0 CP (28.7 CP for Q95\%). Under this scenario, farmers cultivating temperate species in southern Brazil may face severe challenges during the dormancy phase. Providing these farmers with an adequate portfolio of strategies to adapt their orchards to the negative impacts of climate change may become critical for sustaining temperate fruit production.

The application of dormancy-breaking agents is a horticultural practice that may help farmers overcome dormancy-related problems caused by insufficient winter chill. Hydrogen cyanamide, gibberellic acid, and potassium nitrate have successfully been used to promote dormancy release and bud burst in grapevines, Japanese apricots, and pistachios (Perez and Lira 2005; Rahemi and Asghari 2004; Zhuang et al. 2013). For this strategy to be effective, however, a minimum amount of chill (e.g., about $70 \%$ of the trees' chill requirement) must have been accumulated by the trees before the chemical is applied (Erez 2000). This basic need limits the application of dormancy-breaking agents to regions with at least some winter chill accumulation, such as central and southern-central Chile and northern Patagonia. In warmer areas (e.g., southern Brazil), farmers may have to develop medium- and long-term strategies to secure temperate fruit production in the future. In this regard, shifting the array of species to low-chill genotypes may offer farmers an opportunity to adapt their orchards to the impacts of climate change. Nonetheless, adopting radical adaptation strategies (e.g., shifting species) is often a decision that farmers hesitate to make because of cultural, market-related, and personal preferences (Nguyen and Drakou 2021).

Developing new low-chill cultivars appears as a promising strategy to help farmers face future challenges while retaining their current production practices for a given species. Breeding new cultivars is, however, a challenging task that requires considering a number of variables such as productivity, consumer preferences, and susceptibility to diseases and growth disorders (Sherman and Beckman 2003). Similarly, breeding programs face the challenge of estimating and reporting the cold requirement of trees, since all metrics to make such estimates were developed more than three decades ago, and none have been fully convincing. Currently available chill models have shown low transferability of estimates among regions (Luedeling 2012; Luedeling and Brown 2011), making reported cultivar-specific chill requirements uninformative for most regions that are different from 
those where the initial estimation was conducted. In the case of the Dynamic Model, for instance, most farmers and researchers still use the model with the original set of parameters for peach trees reported 30 years ago (Erez et al. 1990; Fishman et al. 1987a, 1987b), although current knowledge suggests that model parameters should be adjusted for each species, and possibly each cultivar (Campoy et al. 2011; Fadón et al. 2020a). Recent studies suggest a need to re-parameterize the Dynamic Model depending on the species and cultivar evaluated (Egea et al. 2020). Similarly, Luedeling et al. (2021) recently proposed a modelling framework that considers the climatic needs of trees during both the endo- and eco-dormancy phases to predict bloom dates. Including a cultivar-specific re-parameterization, as well as a framework considering the whole dormant phase, is expected to help breeders identify genotypes that are well-adapted to future climatic challenges. Farmers growing cultivars that remain economically viable under future scenarios should be able to secure the viability of temperate fruit production in South America and possibly other warm-winter regions.

\section{Conclusions}

Our results raise concerns regarding future chill levels in some areas of South America such as northern Patagonia, southern Brazil, and northern-central Chile. To secure temperate fruit production in these regions, farmers cultivating high-chill species might need to develop new medium- and long-term strategies. Among these, we suggest the cultivation of genotypes with lower chill requirements that are aligned with local conditions under future scenarios. Some regions are likely to be relatively unaffected by chill losses. In southern regions of Chile and Argentina, future chill levels may remain sufficient for overcoming dormancy in temperate fruit species. However, some horticultural practices such as the application of dormancy-breaking agents may play a role in sustaining adequate yields after warm winters. The method we used for interpolating Safe Winter Chill helped estimate chill levels in regions where long-term high-resolution data are scarce. Despite some limitations of the method (low accuracy in high-elevation regions), which indicate a need for additional research, our approach can help provide farmers with reasonable estimates of future chill levels. Estimations of future chill levels help farmers, orchard managers, and relevant stakeholders make decisions on future developments and planning regarding the temperate fruit industry.

Supplementary Information The online version contains supplementary material available at https://doi. org/10.1007/s10584-021-03276-w.

Acknowledgements We would like to thank Ricardo del Barrio for providing the weather data from the Argentinean databases as well as the Center for Climate and Resilience Research $\left([\mathrm{CR}]^{2}\right)$ of the University of Chile for making the weather data from Chile publicly available.

Author contribution EL conceived the research idea and guided EF in establishing the research framework. EF implemented the procedure to obtain the weather data and generate future scenarios based on a method developed by EL. LC and II implemented the interpolation procedure with the guidance of EF and EL. II, LC, and EF wrote the first version of the manuscript with EL commenting on and editing the draft. The authors contributed to analyzing and discussing the results.

Funding Open Access funding enabled and organized by Projekt DEAL. We thank the Partnership for Research and Innovation in the Mediterranean Area (PRIMA), a program supported under H2020, the European Union's Framework program for research and innovation, for funding this research within the 
AdaMedOr project (grant number 01DH20012 of the German Federal Ministry of Education and Research). Bundesministerium für Bildung und Forschung,01DH20012,Eike Luedeling

Data availability Scripts for data downloading and reproduction of all data processing steps (including figure generation) are available in a public GitHub repository (https://github.com/EduardoFernandezC/chill_ south_america).

\section{Declarations}

Conflict of interest This research was conducted in the absence of any relationship that can construct a possible conflict of interest.

Open Access This article is licensed under a Creative Commons Attribution 4.0 International License, which permits use, sharing, adaptation, distribution and reproduction in any medium or format, as long as you give appropriate credit to the original author(s) and the source, provide a link to the Creative Commons licence, and indicate if changes were made. The images or other third party material in this article are included in the article's Creative Commons licence, unless indicated otherwise in a credit line to the material. If material is not included in the article's Creative Commons licence and your intended use is not permitted by statutory regulation or exceeds the permitted use, you will need to obtain permission directly from the copyright holder. To view a copy of this licence, visit http://creativecommons.org/licenses/by/4.0/.

\section{References}

Alburquerque N, Garcia-Montiel F, Carrillo A, Burgos L (2008) Chilling and heat requirements of sweet cherry cultivars and the relationship between altitude and the probability of satisfying the chill requirements. Environ Exp Bot 64:162-170. https://doi.org/10.1016/j.envexpbot.2008.01.003

Allen MR et al (2018) Framing and context. In: Masson-Delmotte V et al. (eds) Global Warming of $1.5^{\circ} \mathrm{C}$. An IPCC Special Report on the impacts of global warming of $1.5^{\circ} \mathrm{C}$ above pre-industrial levels and related global greenhouse gas emission pathways, in the context of strengthening the global response to the threat of climate change, sustainable development, and efforts to eradicate poverty. In Press.

Almorox J, Hontoria C, Benito M (2005) Statistical validation of daylength definitions for estimation of global solar radiation in Toledo, Spain. Energy Convers Manage 46:1465-1471. https://doi.org/10. 1016/j.enconman.2004.07.007

Benmoussa H, Luedeling E, Ghrab M, Ben Mimoun M (2020) Severe winter chill decline impacts Tunisian fruit and nut orchards. Clim Change 162:1249-1267. https://doi.org/10.1007/s10584-020-02774-7

Buerkert A, Fernandez E, Tietjen B, Luedeling E (2020) Revisiting climate change effects on winter chill in mountain oases of northern Oman. Clim Change 162:1399-1417. https://doi.org/10.1007/ s10584-020-02862-8

CAFI (2019) Producción de peras y manzanas en Argentina. URL: http://www.cafi.org.ar/produccion-deperas-y-manzanas-en-argentina/ accessed July 5th, 2019

Campoy JA, Ruiz D, Egea J (2011) Dormancy in temperate fruit trees in a global warming context: a review. Sci Hortic 130:357-372. https://doi.org/10.1016/j.scienta.2011.07.011

Cordano E, Eccel E (2019) RMAWGEN (R Multi-site Auto-regressive Weather GENerator), a package to generate daily time series of precipitation and temperature from monthly mean values. R Package Version 1(3):7

Darbyshire R, Measham P, Goodwin I (2016) A crop and cultivar-specific approach to assess future winter chill risk for fruit and nut trees. Clim Change 137:541-556. https://doi.org/10.1007/s10584-016-1692-3

del Barrio R, Fernandez E, Brendel AS, Whitney C, Campoy JA, Luedeling E (2021) Climate change impacts on agriculture's southern frontier - perspectives for farming in North Patagonia. Int J Climatol 41:726-742. https://doi.org/10.1002/joc.6649

Delgado A, Egea JA, Luedeling E, Dapena E (2021) Agroclimatic requirements and phenological responses to climate change of local apple cultivars in northwestern Spain. Sci Hortic 283:110093. https://doi. org/10.1016/j.scienta.2021.110093

Denardi F, Kvitschal MV, Hawerroth MC (2019) A brief history of the forty-five years of the Epagri apple breeding program in Brazil. Crop Breed Appl Biotechnol 19:347-355. https://doi.org/10.1590/198470332019v19n3p47 
Egea JA, Egea J, Ruiz D (2020) Reducing the uncertainty on chilling requirements for endodormancy breaking of temperate fruits by data-based parameter estimation of the dynamic model: a test case in apricot. Tree Physiol 41:644-656. https://doi.org/10.1093/treephys/tpaa054

Erez A (2000) Bud dormancy; phenomenon, problems and solutions in the tropics and subtropics. In: Erez A (ed) Temperate Fruit Crops in Warm Climates. Springer Netherlands, Dordrecht, pp 17-48. https:// doi.org/10.1007/978-94-017-3215-4_2

Erez A, Fishman S, Linsley-Noakes GC, Allan P (1990) The dynamic model for rest completion in peach buds. Acta Hort 276:165-174

Fadón E, Fernandez E, Behn H, Luedeling E (2020a) A conceptual framework for winter dormancy in deciduous trees. Agronomy 10:241. https://doi.org/10.3390/agronomy10020241

Fadón E, Herrera S, Guerrero BI, Guerra ME, Rodrigo J (2020b) Chilling and heat requirements of temperate stone fruit trees (Prunus sp.). Agronomy-Basel 10:32. https://doi.org/10.3390/agronomy10030409

Fernandez E (2020) dormancyR: functions to compute chill metrics. R package version 0.1.41

Fernandez E, Luedeling E, Behrend D, Van de Vliet S, Kunz A, Fadón E (2020a) Mild water stress makes apple buds more likely to flower and more responsive to artificial forcing - impacts of an unusually warm and dry summer in Germany. Agronomy 10:274. https://doi.org/10.3390/agronomy10020274

Fernandez E, Whitney C, Cuneo IF, Luedeling E (2020b) Prospects of decreasing winter chill for deciduous fruit production in Chile throughout the 21st century. Clim Change 159:423-439. https://doi.org/10. 1007/s10584-019-02608-1

Fernandez E, Whitney C, Luedeling E (2020c) The importance of chill model selection - a multi-site analysis. Eur J Agron 119:126103. https://doi.org/10.1016/j.eja.2020.126103

Fick SE, Hijmans RJ (2017) WorldClim 2: new 1-km spatial resolution climate surfaces for global land areas. Int J Climatol 37:4302-4315. https://doi.org/10.1002/joc.5086

Fishman S, Erez A, Couvillon GA (1987a) The temperature-dependence of dormancy breaking in plants computer-simulation of processes studied under controlled temperatures. J Theor Biol 126:309-321. https://doi.org/10.1016/s0022-5193(87)80237-0

Fishman S, Erez A, Couvillon GA (1987b) The temperature-dependence of dormancy breaking in plants mathematical-analysis of a 2-step model involving a cooperative transition. J Theor Biol 124:473-483. https://doi.org/10.1016/s0022-5193(87)80221-7

Girvetz EH, Zganjar C, Raber GT, Maurer EP, Kareiva P, Lawler JJ (2009) Applied climate-change analysis: the Climate Wizard tool. PLoS ONE 4. https://doi.org/10.1371/journal.pone.0008320

Global Change (2021) Emissions, concentrations, and temperature projections. URL: https://www.globa lchange.gov/browse/multimedia/emissions-concentrations-and-temperature-projections accessed June 1 st, 2021

IPCC (2014) Climate Change 2014: Synthesis report. Contributions of working groups I, II and III to the fifth assesment report of the Intergovernmental Panel on Climate Change Core Writing Team, R.K. Pachauri, Meyer LA (eds). IPCC, Geneva, Switzerland.

IPCC (2021) Summary for policymakers. Masson-Delmotte V et al. (eds). Cambrige University Press

Kwon JH, Nam EY, Yun SK, Kim SJ, Song SY, Lee JH, Hwang KD (2020) Chilling and heat requirement of peach cultivars and changes in chilling accumulation spectrums based on 100-year records in Republic of Korea. Agric For Meteorol 288:10. https://doi.org/10.1016/j.agrformet.2020.108009

Lavee S, May P (1997) Dormancy of grapevine buds - facts and speculation. Aust J Grape Wine R 3:31-46. https://doi.org/10.1111/j.1755-0238.1997.tb00114.x

Linvill DE (1990) Calculating chilling hours and chill units from daily maximum and minimum temperature observations. HortScience 25:14-16

Luedeling E (2012) Climate change impacts on winter chill for temperate fruit and nut production: a review. Sci Hortic 144:218-229. https://doi.org/10.1016/j.scienta.2012.07.011

Luedeling E (2018) Interpolating hourly temperatures for computing agroclimatic metrics. Int J Biometeorol 62:1799-1807. https://doi.org/10.1007/s00484-018-1582-7

Luedeling E (2020) chillR: statistical methods for phenology analysis in temperate fruit trees. R package version 0.70 .24

Luedeling E, Brown PH (2011) A global analysis of the comparability of winter chill models for fruit and nut trees. Int J Biometeorol 55:411-421. https://doi.org/10.1007/s00484-010-0352-y

Luedeling E, Girvetz EH, Semenov MA, Brown PH (2011) Climate change affects winter chill for temperate fruit and nut trees. PLoS ONE 6:13. https://doi.org/10.1371/journal.pone.0020155

Luedeling E, Schiffers K, Fohrmann T, Urbach C (2021) PhenoFlex - an integrated model to predict spring phenology in temperate fruit trees. Agric for Meteorol 307:108491. https://doi.org/10.1016/j.agrfo rmet.2021.108491

Luedeling E, Zhang MH, Girvetz EH (2009) Climatic changes lead to declining winter chill for fruit and nut trees in California during 1950-2099. PLoS ONE 4:9. https://doi.org/10.1371/journal.pone.0006166 
Nguyen N, Drakou EG (2021) Farmers intention to adopt sustainable agriculture hinges on climate awareness: the case of Vietnamese coffee. J Clean Prod 303. https://doi.org/10.1016/j.jclepro.2021.126828

Nychka D, Furrer R, Paige J, Sain S (2017) fields: tools for spatial data. R Package Version 10:3

ODEPA (2017) Chilean agriculture overview. Office of Agricultural Studies and Policies, Santiago, Chile

Parkes H, Darbyshire R, White N (2020) Chilling requirements of apple cultivars grown in mild Australian winter conditions. Sci Hortic 260:8. https://doi.org/10.1016/j.scienta.2019.108858

Perez FJ, Lira W (2005) Possible role of catalase in post-dormancy bud break in grapevines. J Plant Physiol 162:301-308. https://doi.org/10.1016/j.jplph.2004.07.011

R Core Team (2020) R: a language and environment for statistical computing. R Foundation for Statistical Computing. Version 4.0.0 Vienna, Austria

Rahemi M, Asghari H (2004) Effect of hydrogen cyanamide (dormex), yolk oil and potassium nitrate on budbreak, yield and nut characteristics of pistachio (Pistacia vera L.). J Horticult Sci Biotechnol 79:823-827. https://doi.org/10.1080/14620316.2004.11511849

Richardson EA, Seeley SD, Walker DR (1974) A model for estimating the completion of rest for "Redhaven" and "Elberta" peach trees. HortScience 1:331-332

Rodríguez A, Pérez-López D, Sánchez E, Centeno A, Gómara I, Dosio A, Ruiz-Ramos M (2019) Chilling accumulation in fruit trees in Spain under climate change. Nat Hazards Earth Syst Sci 19:1087-1103. https://doi.org/10.5194/nhess-19-1087-2019

Saure MC (1985) Dormancy release in deciduous fruit trees. Hortic Rev 7:239-300

Sherman WB, Beckman TG Climatic adaptation in fruit crops. In, 2003. International Society for Horticultural Science (ISHS), Leuven, Belgium, pp 411-428. https://doi.org/10.17660/ActaHortic.2003.622.43

Tennekes M (2018) tmap: thematic maps in R. J Stat Softw 84:1-39. https://doi.org/10.18637/jss.v084.i06

van Vuuren DP et al (2011) The representative concentration pathways: an overview. Clim Change 109:5. https://doi.org/10.1007/s10584-011-0148-z

Vegis A (1964) Dormancy in higher plants. Annu Rev Plant Physiol 15:185-224. https://doi.org/10.1146/ annurev.pp.15.060164.001153

Weinberger JH (1950) Chilling requirements of peach varieties. Proc Am Soc Hortic Sci 56:122-128

Wickham H (2016) ggplot2: elegant graphics for data analysis. R. Package, New York

Wilks DS, Wilby RL (1999) The weather generation game: a review of stochastic weather models. Prog Phys Geogr 23:329-357. https://doi.org/10.1191/030913399666525256

Wrege MS, Caramori PH, Herter FG, Steinmetz S, Reisser Júnior C, Matzenauer R, Braga HJ Impact of global warming on the accumulated Chilling Hours in the southern region of Brazil. In, 2010. International Society for Horticultural Science (ISHS), Leuven, Belgium, pp 31-40. https://doi.org/10.17660/ ActaHortic.2010.872.2

Zhang JL, Taylor C (2011) The Dynamic Model provides the best description of the chill process on "Sirora" pistachio trees in Australia. HortScience 46:420-425

Zhuang W, Gao Z, Wang L, Zhong W, Ni Z, Zhang Z (2013) Comparative proteomic and transcriptomic approaches to address the active role of GA4 in Japanese apricot flower bud dormancy release. J Exp Bot 64:4953-4966. https://doi.org/10.1093/jxb/ert284

Publisher's note Springer Nature remains neutral with regard to jurisdictional claims in published maps and institutional affiliations. 